\title{
Impact of hiatal hernia on histological pattern of non-erosive reflux disease
}

\author{
Anthie Gatopoulou1 ${ }^{1}$, Konstantinos Mimidis*1,2, Alexandra Giatromanolaki ${ }^{3}$, \\ Vassilios Papadopoulos ${ }^{2}$, Alexandros Polychronidis ${ }^{4}$, \\ Nikolaos Lyratzopoulos ${ }^{4}$, Efthimios Sivridis ${ }^{3}$ and Georgios Minopoulos ${ }^{1,5}$
}

\begin{abstract}
Address: ${ }^{1}$ Endoscopy Unit, Democritus University of Thrace, Dragana, GR-68100 Alexandroupolis, Greece, ${ }^{2}$ First Department of Internal Medicine, Democritus University of Thrace, Dragana, GR-68100 Alexandroupolis, Greece, ${ }^{3}$ Department of Pathology, Democritus University of Thrace, Dragana, GR-68100 Alexandroupolis, Greece, ${ }^{4}$ Second Department of Surgery, Democritus University of Thrace, Dragana, GR-68100 Alexandroupolis, Greece and 5First Department of Surgery, Democritus University of Thrace, Dragana, GR-68100 Alexandroupolis, Greece

Email: Anthie Gatopoulou - gatop@otenet.gr; Konstantinos Mimidis* - kmimidis@otenet.gr; Alexandra Giatromanolaki - kmimidis@otenet.gr; Vassilios Papadopoulos - vaspapmd@mail.otenet.gr; Alexandros Polychronidis - kmimidis@otenet.gr;

Nikolaos Lyratzopoulos - kmimidis@otenet.gr; Efthimios Sivridis - kmimidis@otenet.gr; Georgios Minopoulos - kmimidis@otenet.gr

* Corresponding author
\end{abstract}

Published: 09 January 2005

BMC Gastroenterology 2005, 5:2 doi:10.1/86/147/-230X-5-2
Received: 27 June 2004

Accepted: 09 January 2005

This article is available from: http://www.biomedcentral.com/I47I-230X/5/2

(c) 2005 Gatopoulou et al; licensee BioMed Central Ltd.

This is an Open Access article distributed under the terms of the Creative Commons Attribution License (http://creativecommons.org/licenses/by/2.0), which permits unrestricted use, distribution, and reproduction in any medium, provided the original work is properly cited.

\begin{abstract}
Background: Hiatus hernia $(\mathrm{HH})$ has major pathophysiological effects favoring gastroesophageal reflux and hence contributing to esophageal mucosa injury, especially in patients with severe gastroesophageal disease. However, prospective studies investigating the impact of $\mathrm{HH}$ on the esophageal mucosa in non-erosive reflux disease (NERD) are lacking. This study evaluated the association between the presence of $(\mathrm{HH})$ and the histological findings in symptomatic patients with NERD.
\end{abstract}

Methods: Fifty consecutive patients with gastroesophageal reflux disease (GERD) were enrolled. After conventional endoscopy, Lugol solution was applied and biopsy specimens were obtained. Histological parameters including basal zone hyperplasia, papillary length and cellular infiltration were evaluated. The chi-square test with Yates' correlation was used for comparing discrete parameters between groups. However, Fisher's exact probability test was used where the expected frequencies were lower than 5 . Wilcoxon's test for unpaired samples was preferred in cases of semi-quantitative parameters.

Results: The presence of $\mathrm{HH}$ along with more severe findings $(0.0 \mathrm{I}<P<0.05)$ was confirmed in 18 patients. NERD was observed in $29(58 \%)$ patients. Basal zone hyperplasia and loss of glycogen accompanied $\mathrm{HH}$ in all cases, and the correlation was significant in NERD $(P<0.00 \mathrm{I})$. The remaining histological patterns were similar between erosive reflux disease and NERD in the presence of $\mathrm{HH}$.

Conclusion: The presence of $\mathrm{HH}$ is correlated with more severe endoscopy findings, and predisposes for severe histological abnormality in cases of NERD. 


\section{Background}

Gastroesophageal reflux disease (GERD) is a common condition that affects $25-30 \%$ of the population [1]. It clearly involves multifactorial pathophysiology, yet the factors underlying why only some patients develop reflux esophagitis are unclear [2].

Symptoms and demographic data do not allow differentiation between the endoscopy-negative (non-erosive reflux disease; NERD) and endoscopy-positive (erosive reflux disease; ERD) forms of the disease. In fact most patients with typical symptoms of GERD have normal esophageal mucosa on upper endoscopy. Indeed, more than twothirds of all patients with reflux symptoms never develop esophageal erosions, ulcers or strictures [3]. This group of NERD patients constitutes a significant clinical problem since they appear to be relatively resistant to proton-pump inhibitors (PPIs) [4,5].

Hiatal hernia ( $\mathrm{HH}$ ) has been considered to be one of the pathophysiological mechanisms that contributes to the development of GERD, promoting refluxate access and impaired acid clearance; however, the impact of this mechanism in NERD is unclear $[2,6,7]$.

The aim of the present study was to clarify the possible association of $\mathrm{HH}$ with histological findings on a group of prospectively studied symptomatic patients with NERD.

\section{Methods}

Fifty patients $(29$ men, 21 women; aged $49.9 \pm 6.6$ years, mean \pm SD) were evaluated prospectively in our endoscopy unit for symptoms compatible with GERD, namely heartburn, acid regurgitation and belching. A standardized questionnaire was completed for each patient during an interview with an experienced gastroenterologist. Demographic details of the GERD patients were recorded, including age, sex, smoking habits, tea, coffee and alcohol consumption, and concurrent medical conditions including hypertension and diabetes mellitus.

None of the patients included in this study had a current or past history of peptic ulcer disease, previous gastric surgery, antihelicobacter therapy, or use of PPIs, non-steroidal anti-inflammatory drugs, steroids or tetracycline during the previous 4 weeks. Ethics approval was obtained from the ethics committee of the University Hospital of Alexandroupolis, and patients provided signed, informed consent for their biopsy specimens to be taken.

Routine endoscopy was performed in all patients by the same endoscopist using a flexible endoscope (GIF-Q145, Olympus). The distance between the esophagogastric junction and the incisor teeth was recorded. Reflux esophagitis was graded in accordance with the Los Angeles classification [8]. HH was considered present if gastric folds were assessed as extending $\geq 2 \mathrm{~cm}$ above the diaphragmatic hiatus during quiet respiration [2].

At least four biopsy specimens were taken at $3 \mathrm{~cm}$ above the lower esophageal sphincter with biopsy forceps (Olympus) in a criss-cross manner. In order to improve endoscopic visualization and provide biopsy orientation, $20 \mathrm{ml}$ of $2 \%$ potassium iodine solution (Lugol) was applied through a "spray" catheter [9-11]. To obtain sufficient material and to ensure an almost vertical pinch biopsy specimen, the opened forceps were withdrawn towards the tip of the endoscope, which was bent forwards maximally, and hence the forceps were pressed vertically against the esophageal wall. Specimens were fixed in $40 \mathrm{mg} / \mathrm{L}$ formaldehyde [12].

After all the sections had been obtained, they were assessed histologically in a blinded manner (i.e. without endoscopic or clinical information). Standardized reports completed by the histopathologist comprised an evaluation of the following histological parameters: basal zone hyperplasia, papillary length, dilatation of intraepithelial blood vessels, and semi-quantitative cellular infiltration by T-lymphocytes, neutrophils and eosinophils. Alterations in glycogen content, erosion, ulceration and chronic inflammation were also assessed as described previously [12-17].

The chi-square test with Yates' correlation was used to compare discrete parameters between groups. However, Fisher's exact probability test was used where expected frequencies were lower than 5. Wilcoxon's test for unpaired samples was preferred in cases of semi-quantitative parameters due to its greater power. Mean values and their 95\% confidence limits were calculated. Statistical significance was set at $P \leq 0.05$. All analyses were performed using the statistical software package "Statistica (version 6)".

\section{Results \\ Endoscopy findings}

Endoscopy revealed esophageal mucosa with a normal appearance in 29 patients. The remaining 21 patients had esophagitis of variable severity (Table 1).

$\mathrm{HH}$ was observed in 18 patients. Its presence $(\mathrm{HH}+)$ was correlated not only with the presence of erosions $(P=$ 0.0196 ) (Figure 1), but also with the severity of the endoscopy findings (Wilcoxon's $T_{1}$ score for unpaired samples: 576 for $N_{1}=18$ and $N_{2}=32,0.01<P<0.05$ ) (Figure 2). 
Table I: Endoscopy findings in patients with reflux disease. Endoscopy findings in patients with reflux disease, for $\mathrm{HH}+$ and $\mathrm{HH}$.

\begin{tabular}{lcccccc}
\hline & NERD & ERD grade A & ERD grade B & ERD grade C & ERD grade D & Total \\
\hline $\mathrm{HH}+$ & 7 & 5 & 4 & 2 & 0 & 18 \\
$\mathrm{HH}-$ & 22 & 8 & 2 & 0 & 0 & 32 \\
Total & 29 & 13 & 6 & 2 & 0 & 50 \\
\hline
\end{tabular}

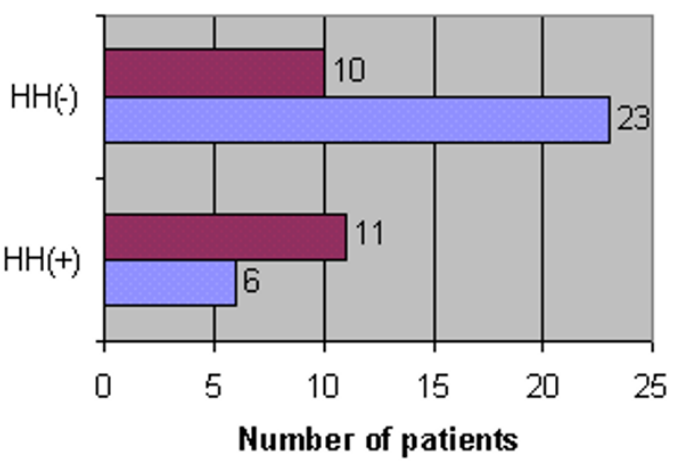

Figure I

Prevalence of $\mathrm{HH}$ among ERD and NERD patients. Prevalence of $\mathrm{HH}$ among ERD and NERD patients. $P=$ 0.0196 when $\mathrm{HH}+$ and $\mathrm{HH}$ - are compared.

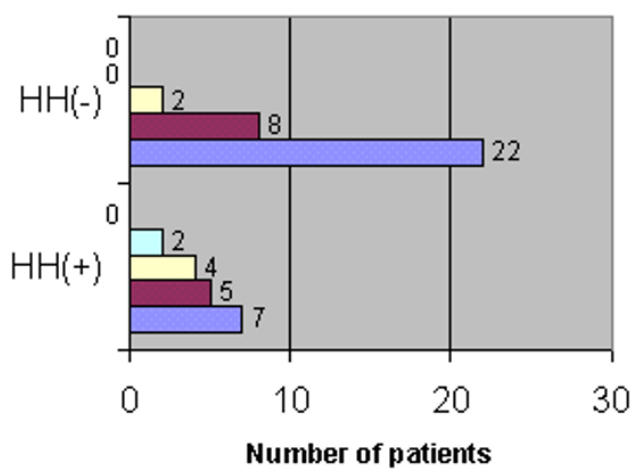

QERD grade $\mathrm{D}$ पERD grade C QERD grade $\mathrm{B}$ 口ERD grade A QNERD

Figure 2

Relationship between $\mathrm{HH}$ and endoscopy findings (0.0 I < $<$ 0.05). Relationship between $\mathrm{HH}$ and endoscopy findings. $0.0 \mathrm{I}<P<0.05$ when $\mathrm{HH}+$ and $\mathrm{HH}$ - are compared.

\section{Histological findings}

Histological examinations of the biopsy specimens revealed esophagitis in 46 out of 48 patients, despite the normal appearance of the esophageal mucosa in most of them. Two specimens - one from a patient with ERD with

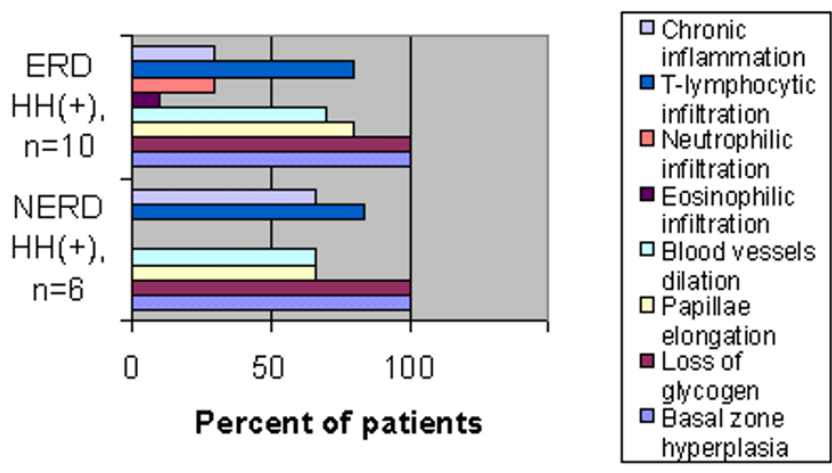

Figure 3

Histological findings among ERD and NERD patients in the presence of $\mathrm{HH}$. Histological findings among ERD and NERD patients in the presence of $\mathrm{HH}$. Basal zone hyperplasia and loss of glycogen is a ubiquitous histological feature in both ERD and NERD with $\mathrm{HH}$. No statistically significant difference was observed between ERD and NERD with $\mathrm{HH}$ in any of the histological findings.

$\mathrm{HH}$ and one from a patient with NERD with $\mathrm{HH}$ - were quantitatively inadequate and thus omitted.

Although the remaining histological patterns were similar between ERD and NERD in $\mathrm{HH}+$ (Figure 3), basal zone hyperplasia and loss of glycogen accompanied $\mathrm{HH}$ in all cases, with the correlation being highly significant in NERD $\left(P=2.61 \times 10^{-6}\right)$ (Figure 4$)$.

\section{Discussion}

The clinical spectrum of GERD is diverse. The disease follows a rather benign course in most patients. Indeed, it is estimated that NERD accounts for up to $70 \%$ of patients with GERD [1]. The pathophysiological mechanisms that contribute to the development of GERD include delayed gastric emptying, frequent and transient relaxation of the lower esophageal sphincter, impaired esophageal clearance of regurgitated gastric acid, and $\mathrm{HH}+[2]$.

$\mathrm{HH}$ has recently re-emerged as an important factor in GERD $[6,7,18]$. It may diminish lower esophageal 


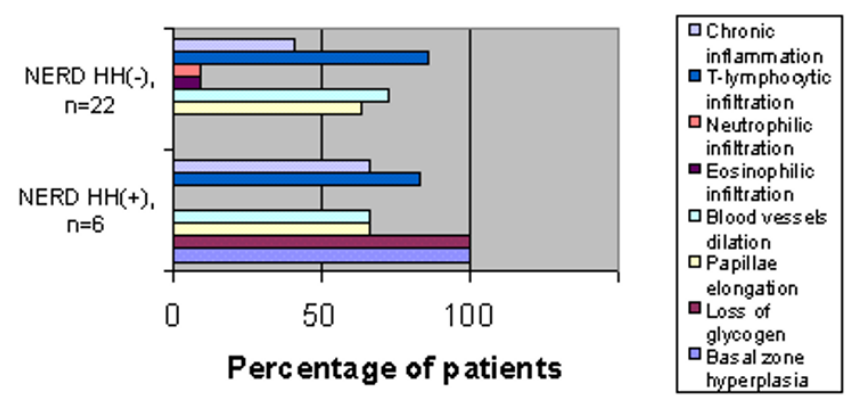

Figure 4

Histological findings among NERD patients with and without hernia. Histological findings among NERD patients with and without hernia. $P=2.61 \times 10^{-6}$ for basal zone hyperplasia and papillary elongation.

sphincter pressure, promote acid reflux and compromise emptying of the refluxate from the distal esophagus, prolonging acid contact with the esophageal mucosa [19-21], a mechanism that could explain the association of $\mathrm{HH}$ with more severe reflux $[22,23]$. Thus, although HH has been established as the strongest predictor of the presence and severity of esophagitis in GERD patients with esophagitis, there are no published data on the role of $\mathrm{HH}$ in symptomatic patients without endoscopic esophagitis.

Our prospective study suggests that $\mathrm{HH}+$, even in patients with an esophageal mucosa that appears normal endoscopically (NERD), indicates the existence of histological effects.

Our population was characterized by similar clinical presentation, and HH was correlated not only with the presence of erosions (Figure 1) but also with the severity of the endoscopy findings (Figure 2). These results further support $\mathrm{HH}$ as a dominant predictive factor for erosive esophagitis, which has already been confirmed in previous studies [2,24-27].

In order to further investigate the role of HH in NERD patients, we studied the role of $\mathrm{HH}+$ on the histological parameters of esophagitis. In our material, basal zone hyperplasia and loss of glycogen content was detected in all HH+ ERD patients and HH+ NERD patients (Figure 3). In contrast, no NERD patient without $\mathrm{HH}(\mathrm{HH}-)$ exhibited similar histological abnormalities (Figure 4). These findings probably indicate that the development of NERD in $\mathrm{HH}+$ patients is more closely related to the pathophysiology of ERD, and perhaps different from the mechanisms responsible for NERD in HH- patients.
Little is known about the relationship between HH and the histological variables in non-erosive esophagitis. Our finding that basal zone hyperplasia and loss of glycogen content are more frequently prevalent in $\mathrm{HH}+$ than in HH- among NERD patients as well as the fact that basal zone hyperplasia, loss of glycogen content and infiltration with T-lymphocytes are more frequent in ERD than in NERD suggests the that $\mathrm{HH}$ contributes directly to the development of both GERD and NERD, perhaps through decreased acid clearance.

\section{Conclusions}

$\mathrm{HH}+$ not only appears to be a risk factor for NERD, but is also suggestive of the histological presence of microscopic GERD in symptomatic NERD patients. This finding could play an important role in the therapeutic management of NERD patients with PPIs in the future, since ERD patients respond better than NERD patients to antireflux therapy. Future studies should establish whether there is a causeand-effect relationship between $\mathrm{HH}$ and response to PPIs in NERD patients.

\section{List of abbreviations}

HH: Hiatal hernia

NERD: Non-erosive reflux disease

GERD: Gastroesophageal reflux disease

ERD: Erosive reflux disease

$\mathrm{HH}+$ : Presence of hiatal hernia

HH-: Absence of hiatal hernia

PPI: Proton-pump inhibitors

\section{Competing interests}

The author(s) declare that they have no competing interests.

\section{Authors' contributions}

A.G. participated in the endoscopy studies and in the preparation of the manuscript.

K.M. participated in the endoscopy studies and in the preparation of the manuscript.

A.G. participated in the histological studies.

V.P. contributed to the design of the study, performed the statistical analysis and produced the graphical presentations of the results.

E.S. participated in the histopathological studies. 
A.P. contributed to the design of the study and critically reviewed the manuscript.

N.L. contributed to the design of the study and critically reviewed the manuscript.

\section{G.M. coordinated the study.}

All the authors read and approved the final version of the manuscript.

\section{References}

I. Spechler SJ: Epidemiology and natural history of gastroesophageal reflux disease. Digestion 1992, 5 I:24-29.

2. Avidam B, Sonnenberg A, Schnell TG, Sontag SJ: Risk factors for erosive reflux esophagitis: a case control study. Am J Gastroenterol 200I, 96:4|-46.

3. Sonnenberg A: Esophageal disease. In Digestive disease in the United States: Epidemiology and impact Edited by: Everhart JE. Washington, DC: U.S. Government printing office, NIH publication 94-1447; 1994:299-356.

4. Kahrilas PJ: Diagnosis of symptomatic gastro-oesophageal reflux disease. Am J Gastroenterol 2003, 98: I5-23.

5. Smout AJ: Endoscopy-negative acid reflux disease. Aliment Pharmacol Ther 1997, II:81-85.

6. Dent J: The hiatal hernia slides back into prominence. Gut 1999, 44:449-450.

7. Murray JA, Camilleri M: The fall and the rise of hiatal hernia. Gastroenterology 2000, I 19:1779-1794.

8. Dent J, Brun J, Fendrick A, Fennerty MB, Janssens J, Kahrilas PJ, Lauritsen K, Reynolds JC, Shaw M, Talley NJ, on behalf of the Genval Workshop Group: An evidence based appraisal of reflux disease management - The Genval Workshop Report. Gut 1999, 44:I-16.

9. Rajan E, Burgart JL, Gostout JC: Endoscopic and histologic diagnosis of Barrett esophagus. Mayo Clin Proc 200I, 76:217-225.

10. Tincani AJ, Brandalise N, Altemani A, Scanavini RC, Valerio JB, Lage HT, Molina G, Martins AS: Diagnosis of superficial esophageal cancer and dysplasia using endoscopic screening with $2 \%$ Lugol dye solution in patients with head and neck cancer. Head Neck 2000, 22: 170-174.

II. Canto MI: Vital staining and Barrett's esophagus. Gastrointest Endosc 1999, 49:12-16.

12. Schindlbeck NE, Wiebecke B, Klauser AG, Voderholzer WA, MullerLissner SA: Diagnostic value of histology in non-erosive gastroesophageal reflux disease. Gut 1996, 39:15I-154.

13. Riddell RH: What mucosal biopsies have to offer. Aliment Pharmacol Ther 1997, I I(Supp I 2): 19-25.

14. Riddell RH: The biopsy diagnosis of gastroesophageal reflux disease, "carditis", Barrett oesophagus and sequelae of therapy. Am J Surg Pathol 1996, 20:3 I-50.

15. Richter JE, Castell DO: Gastrosophageal reflux: pathogenesis, diagnosis and therapy. Ann Intern Med 1982, 97:93-103.

16. Frierson HF: Histology in the diagnosis of reflux esophagitis. Gastroenterol Clin North Am 1990, 19:631-644.

17. Haggitt RC: Histopathology of reflux - induced esophageal and supraesophageal injuries. Am J Med 2000, 6:109-III.

18. Quigley EM: New developments in the pathophysiology of gastro-oesophageal reflux disease (GERD): Implications for patient management. Aliment Pharmacol Ther 2003, 17:43-51.

19. Van Herawaarden MA, Samson M, Smout AJ: Excess gastroesophageal reflux in patients with hiatus hernia is caused by mechanisms other than transient LES relaxations. Gastroenerology 2000, I 1 9:1439-1446.

20. Sloan S, Redemaker AW, Kahrilas PJ: Determinants of gastroesophageal junction incompetence: hiatal hernia lower esophageal sphincter or both? Ann Intern Med 1992, I I 7:977-982.

21. Mittal RK, Lange R, McCallum RW: Identification and mechanism of delayed esophageal acid clearance in subjects with hiatal hernia. Gastroenterology 1987, 92:। 30 - I 35.

22. Sloan S, Kahrilas PJ: Impairment of esophageal emptying with hiatal hernia. Gastroenterology 1991, 100:596-605.
23. Zhu H, Pace F, Trape E, Sangaletti O, Bianchi Porro G: Prevalence of hiatal hernia and its influence on gastroesophageal reflux. Eur J Gastroenterol Hepatol 1994, 6:393-397.

24. Jones MP, Sloan SS, Rabine JC, Ebert CC, Huang CF, Kahrilas PJ: Hiatal hernia size is the dominant determinant of esophagitis presence and severity in gastroesophageal reflux disease. Am J Gastroenterol 200I, 96: 17I I-I7I7.

25. Yeom JS, Park HJ, Cho JS, Lee SI, Park IS: Reflux esophagitis and its relation to hiatal hernia. J Korean Med Sci 1999, 14:253-256.

26. Sontag SJ, Schnell T, Miller TQ, Nemchausky B, Serlovsky R, O'Connell S, Chejfec G, Seidel UJ, Brand L: The importance of hiatal hernia in reflux esophagitis compared with lower esophageal sphincter pressure or smoking. J Clin Gastroenterol |991, 13:628-643.

27. Petersen $\mathrm{H}$ : The clinical significance of hiatal hernia. Scand J Gastroenterol 1995, 21 I Suppl: 19-20.

\section{Pre-publication history}

The pre-publication history for this paper can be accessed here:

http://www.biomedcentral.com/1471-230X/5/2/prepub
Publish with Biomed Central and every scientist can read your work free of charge

"BioMed Central will be the most significant development for disseminating the results of biomedical research in our lifetime."

Sir Paul Nurse, Cancer Research UK

Your research papers will be:

- available free of charge to the entire biomedical community

- peer reviewed and published immediately upon acceptance

- cited in PubMed and archived on PubMed Central

- yours - you keep the copyright

Submit your manuscript here:

http://www.biomedcentral.com/info/publishing_adv.asp
BiolMedcentral 